\title{
Pengaruh Electronic Money, Gaya Hidup dan Pengendalian Diri Terhadap Perilaku Konsumsi Islam
}

\author{
Maulidysneni Nurvita Sukma ${ }^{1 *)}$, Clarashinta Canggih ${ }^{2)}$ \\ ${ }^{1,2}$ Fakultas Ekonomi, Universitas Negeri Surabaya \\ *Email korespondensi: maulidysnenisukma16081194057@ mhs.unesa.ac.id
}

Penelitian ini bertujuan untuk mengetahui pengaruh electronic money, gaya hidup dan pengendalian diri terhadap pola perilaku konsumsi islam generasi Y dan Z di kota Surabaya. Pola perilaku konsumsi islam diukur dengan enam prinsip dasar konsumsi dalam islam. Metode penelitian yang digunakan yaitu kuantitatif deskriptif. Sampel penelitian ditetapkan sebanyak 150 responden dengan menggunakan rumus Malhotra. Pengumpulan data menggunakan angket dengan metode purposive sampling dan menggunakan skala guttman. Analisis data menggunakan analisis regresi probit menggunakan aplikasi Stata 14. Hasil penelitian menunjukkan bahwa variabel electronic money memiliki nilai marginal effect sebesar $-9,5 \%$ maka probabilitas tidak sesuai pola perilaku konsumsi islami, variabel gaya hidup memiliki nilai sebesar -9\% yang berarti probabilitas tidak sesuai pola perilaku konsumsi islam dan variabel pengendalian diri memiliki nilai sebesar $17 \%$ maka probabilitas sesuai dengan pola perilaku konsumsi islam.

\begin{abstract}
Abstrak
This study was aimed to reveal the impact of electronic money, lifestyle and self control towards Islamic consumption behaviour pattern of $Y$ and $Z$ generation in Surabaya. The behaviour pattern of Islamic consumption was measured by 6 basic principles of consumption in Islam. Descriptive quantitative was applied as the research method. This study took 150 respondents as the research sample by using the formula of Malhotra. The data was collected by using questionnaire along with purposive sampling method and guttman scales. Then, probit regression analysis using the application of Stata 14 was occupied as the data analysis. It was resulted that the variable of electronic money had a marginal effect value of $-9,5 \%$ so that the probability was not correspond to the Islamic consumption behaviour pattern whereas the variable of life style had a value of -9\% which meant that the probability was not correspond to Islamic consumption behaviour pattern and the variable of self control indicated a value of $17 \%$ so that the probability matched with Islamic consumption behaviour pattern.
\end{abstract}

Keywords : Perilaku konsumsi islam, electronic money, gaya hidup, pengendalian diri

Saran sitasi: Sukma, M. N., \& Canggih, C. (2021). Pengaruh Electronic Money, Gaya Hidup dan Pengendalian Diri Terhadap Perilaku Konsumsi Islam. Jurnal Ilmiah Ekonomi Islam, 7(01), 209-215. doi:http://dx.doi.org/10.29040/jiei.v7i1.1570

DOI: http://dx.doi.org/10.29040/jiei.v7i1.1570

\section{PENDAHULUAN}

Konsumsi jika didefinisikan melalui perspektif ekonomi islam maka bisa dinyatakan sebagai upaya manusia dalam memenuhi kebutuhannya baik itu kebutuhan secara fisik ataupun kebutuhan yang non fisik (dalam hal ini rohani) agar bisa menjalankan perannya sebagai hamba Allah SWT dengan maksimal. Seorang muslim dalam berperilaku konsumsi harus didasarkan pada ketentuan islam. Terdapat tujuan atas perilaku konsumsi muslim yaitu halal, Thayyib dan tidak berlebihan (Amir, 2016).
Agama Islam melarang hal yang berlebih- lebihan, karena Islam mempertahankan keseimbangan yang adil. Hal ini terdapat dalam firman Allah SWT QS. AlA'raf Ayat 31:

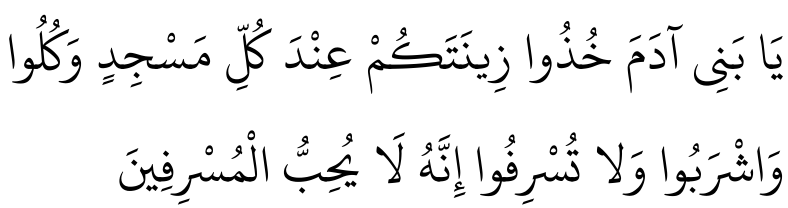

Artinya : "Hai anak Adam, pakailah pakaianmu yang indah di setiap (memasuki) masjid, makan dan 


\section{Jurnal Ilmiah Ekonomi Islam, 7(01), 2021, 210}

minumlah, dan janganlah berlebih-lebihan. Sesungguhnya Allah tidak menyukai orang-orang yang berlebih-lebihan."

Di era digital saat ini, masyarakat dapat dengan mudah dalam bertransaksi secara non-tunai, dan kemudian muncul istilah cashless society (masyarakat tanpa uang tunai). Berkembangnya financial technology pun turut serta menjadi pemicu bermunculannya perusahaan- perusahaan yang mengguluti sector keuangan digital. Salah satu produk dari financial technology ialah uang elektronik $(e-$ money). Menurut data statistik (Bank Indonesia, 2020) yang telah disajikan dalam Gambar 1.1 menunjukkan volume transaksi uang elektronik pada tahun 2013 2019.

Gambar 1.1 Volume Transaksi Uang Elektronik di Indonesia Pada Tahun 2013- 2019

Sumber : Bank Indonesia, 2020

\section{Volume Transaksi Uang Elektronik}

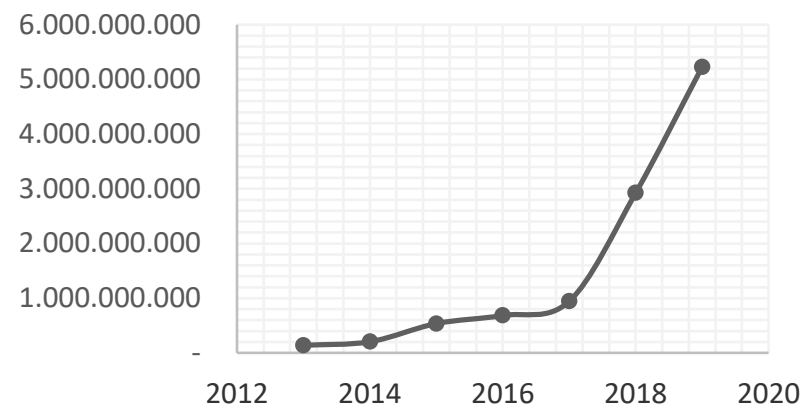

Meskipun e-money telah lama hadir namun perkembangan yang sangat pesat terjadi pada 3 tahun terakhir ini yaitu tahun 2017, 2018, dan 2019 dilihat dari Gambar 1.1 Volume transaksi uang elektronik mengalami kenaikan yang sangat pesat yaitu pada tahun 2017 kemudian mengalami kenaikan pada tahun 2018 dan terus mengalami kenaikan hingga tahun 2019 kenaikan yang lebih dari 100\% dari tahun sebelumnya. Hal ini tidak menutupi kemungkinan bahwa hadirnya uang elektonik dapat mendorong laju perekonomian Indonesia kearah yang lebih baik lagi. Pemakaian e-money mempunyai potensi dimana akan selalu ada peningkatan selaras dengan perkembanganperkembangan teknologi saat ini, terlebih masyarakat disajikan penawaran-penawaran yang menarik dengan cashback, discount dan promosi menarik lainnya yang akhirnya menjadikan masyarakat tergiut dan terus melakukan pemakaian e-money (Delin, 2018). Dalam penelitian (Rif'ah, 2019) memaparkan bahwa fenomena Cashless society sudah menjadikan generasi muda cenderung tidak mengetahui mengenai nilai uang yang mereka miliki. Mereka beranggapan bahwasannya harga ataupun nominal dari transaksi hanyalah sekedar angka, kondisi ini berakibat pada pudarnya nilai mata uang itu sendiri. Kemajuan teknologi sendiri merupakan sesuatu hal yang selalu beriringan dengan zaman dan menjadi bagian yang tak terhindarkan, terkhusus untuk generasi muda yang terbiasa memakainya. Penawaran-penawaran menarik yang menjadi titik poin kelebihan dari system electronic money, telah mendorong generasi muda untuk bergaya hidup cashless. Hal ini mempengaruhi pola dan perilaku konsumsi generasi milenial dalam bertransaksi

Gaya hidup merupakan factor yang turut serta dalam memberikan pengaruh terhadap konsumsi, yang mana gaya hidup sendiri ialah hal yang tidak terpisahkan dari kehidupan sehari-hari. Hal ini memberikan gambaran mengenai sebesar apa nilai moral yang dimiliki seseorang maupun suatu kelompok masyarakat tertentu. Tingginya gaya hidup, disertai dengan zaman yang terus berkembang dan diikuti dengan budaya luar yang bebas mudah masuk sehingga mampu menggeser gaya hidup masyarakat menjadi sedikit berlebihan. Disitulah Gaya hidup memiliki peran terhadap keputusan konsumsi. Dalam menghadapi gaya hidup yang cashless society pada saat ini dibutuhkan adanya upaya pengendalian diri agar tidak terjerumus dalam perilaku konsumsi yang hedonisme ataupun pembelian secara impulsive (Ramadhani, 2019).

Perilaku pengendalian diri merupakan cara seseorang dalam mengontrol atau mengendalikan perilaku. Seorang individu yang mempunyai tingkat pengendalian diri yang tinggi akan melakukan pertimbangan mengenai apakah keputusan perilaku konsumsi itu merupakan aktivitas membeli yang didasarkan atas kebutuhan atau hanya keinginan semata. Pengendalian diri yang baik bisa mencegah dari timbulnya perilaku konsumtif, hal ini dikarenakan dapat mengontrol perilaku kognitif dan keputusannya. Sebagai contoh : seseorang dengan pengendalian diri yang baik dan bijak dalam mengambil keputudan, ketika seseorang tersebut akan berkonsumsi dihadapkan dengan berbagai macam penawaran menarik seperti promo buy 1 get 1 , cashback, ataupun promo menarik lainnya. Ketika menyeleksi pilihanpilihan promo tersebut dengan bijak, dengan memilah- milah mana yang diperlukan dan mana yang 
tidak diperlukan sehingga sesorang tersebut dapat melakukan konsumsi dengan bijak dengan terpenuhi kebutuhannya dan tidak berperilaku konsumtif (Dikria \& W., 2016).

Generasi muda dan gaya hidup cashless society memiliki hubungan erat dengan perkembangan ekonomi digital. Oleh karena itu, generasi muda sebagai generasi yang melek akan teknologi dan hidup didalam "internet of things" dianggap dapat lebih mudah menyesuaikan diri dengan digitalisasi. Tentu saja hal ini sesuai dengan karakteristik dari generasi $Y$ dan $\mathrm{Z}$ yang menyukai segala sesuatu itu praktis dan bisa dikerjakan melalui ponsel atau kartu e-money mereka.

Electronic money merupakan hasil dari perkembangan teknologi yang sedang berkembang saat ini, $e$-money sangat diminati oleh para generasi muda yang sejak kecil sudah diperkenalkan dengan dunia internet. Pemakaian e-money pada generasi muda dapat menunjukkan pola perilaku konsumsinya. Hal tersebut seiring dengan asumsi yang dikemukakan oleh (Khairi \& Gunawan, 2019) bahwa APMK (Alat pembayaran menggunakan kartu) dan electronic money telah menjadi instrument pembayaran yanb baik. Dengan menggunakan indikator minat dan kegunaan, APMK dan E-Money memiliki pengaruh positif dengan pola konsumsi.

Adanya pengaruh gaya hidup pada pola konsumsi masyarakat. Hal tersebut selaras dengan penelitian yang dibuat oleh (Hasibuan, 2019) gaya hidup memiliki pengaruh positif terhadap konsumsi masyarakat muslim di Kecamatan Kotapinang. Sehingga semakin tinggi gaya hidup seseorang maka tingkat konsumsi juga akan semakin tinggi. Hal ini juga dibenarkan oleh penelitian (Mardian Suryani, 2019).

Hubungan antara pengendalian diri terhadap pola perilaku konsumsi dikemukakan dalam penelitian (Dikria \& W., 2016) seseorang yang dapat mengendalikan diri makan akan semakin rendah perilaku konsumtifnya. Hal ini juga dibernarkan oleh penelitian (Ferinaldy et al., 2019) yang menerangkan bahwa kendali perilaku memiliki pengaruh positif terhadap intensi dalam menggunakan uang elektronik. Kendali perilaku positif pada niat perilaku memaparkan bahwasannya masyarakat pemakai emoney mempunyai pengetahuan, kemampuan dan sumber yang baik yang mana mampu memberi pengaruh pada minat masyarakat dalam memakai emoney.
Dalam kehidupan manusia, gaya hidup konsumtif telah mendominasi sulitnya membedakan antara kebutuhan dan keinginan, sehingga berbagai upaya untuk memuaskan keinginan yang ada pada diri manusia. Padahal manusia memiliki kelemahan, sehingga tidak semua keinginan harus terpenuhi. Agama Islam memiliki batas dalam upaya memenuhi kebutuhan manusia. Berdasarkan uraian fenomena yang telah dipaparkan diatas, penelitian mengenai perilaku konsumsi dalam perspektif islam pengguna electronic money menjadi menarik karena gaya hidup adalah faktor yang dapat mempengaruhi seseorang dalam melakukan konsumsi, sedangkan perilaku pengendalian diri diharapankan dapat mengatasi perilaku konsumtif pada pengguna electronic money, kemudian pentingnya mengedepankan tujuan dari konsumsi islam yaitu halal, thayyib dan tidak berlebihan khususnya pada generasi milenial dan generasi $\mathrm{Z}$.

Pada penelitian ini, pembahasan lebih berfokus pada perilaku konsumsi islam, sedangkan penelitian sebelumnya yang dilakukan oleh (Ramadhani, 2019) berfokus pada perilaku konsumtif pada umumnya. Penelitian sebelumnya yang pernah dilakukan mengenai Perilaku konsumsi islam beberapa diantaranya mengambil sampel penelitian dari kalangan mahasiswa seperti penelitian yang dilakukan oleh (Choiriyah, 2019), penelitian (Ramadhani, 2019) dan penelitian (Larasati, 2019). Pembeda penelitian sebelumnya dengan penelitian yang ini adalah penulis memilih untuk meneliti seluruh generasi $\mathrm{Y}$ dan $\mathrm{Z}$ yang bukan hanya dari kalangan mahasiswa, tetapi dari berbagai kalangan.

\section{METODE PENELITIAN}

Penelitian ini merupakan penelitian berjenis kuantitatif, Penelitian ini menganalisis pengaruh electronic money $(\mathrm{X} 1)$, gaya hidup $(\mathrm{X} 2)$, pengendalian diri (X3) terhadap pola perilaku konsumsi islam (Y). Jenis dan sumber data pada penelitian ini adalah sumber data primer karena data yang diperoleh adalah data dari sumber secara langsung dari tangan pertama yaitu Generasi Y dan Z di kota Surabaya.

Populasi yang digunakan dalam penelitian ini adalah masyarakat Kota Surabaya yang berusia 17- 40 tahun. Metode penelitian adalah non probability sampling dimana peneliti memilih purposive sampling, kriteria yang digunakan dalam peneliti dalam memilih sampel adalah generasi $\mathrm{Y}$ dan $\mathrm{Z}$ atau saat ini dalam usia 17-40 tahun, penduduk Kota 
Surabaya, dan pengguna electronic money dalam jangka waktu minimal satu bulan. Teknik pengambilan sampel yang digunakan adalah accidental sampling. Batasan dalam penelitian ini adalah hanya membatasi pada ruang lingkup pengguna e-money yang telah melakukan transaksi selama minimal satu bulan. Adapun jumlah sampel yang ditentukan menggunakan rumus (Malhotra, 2009) yaitu jumlah item pertanyaan dikalikan dengan 5. Item pertanyaan dalam penelitian ini berjumlah 29 x $5=145$ dibulatkan menjadi 150 responden dalam penelitian ini.

Teknik pengumpulan data dilakukan dengan cara menyebarkan kuesioner atau angket secara online dengan menggunakan Google Formulir yang termuat didalamnya pertanyaan- pertanyaan peneliti kepada responden yang telah memenuhi kriteria untuk memperoleh jawaban. Jenis kuesioner yang digunakan adalah jenis kuesioner tertutup, yaitu penyebaran kuesioner dengan jawaban yang sudah disediakanoleh peneliti. Skala pengukuran atas jawaban responden dalam penelitian ini menggunakan skala Guttman.

Teknik analisis data dalam penelitian ini ada dua yaitu uji instrumen penelitian yang terdiri dari Uji Validitas dan Uji Reliabilitas. Kemudian teknik yang kedua yaitu Analisis Regresi Probit. Probit digunakan untuk menganalisis model dengan variabel dependen yang memiliki hasil binnary yaitu $\mathrm{y}=1$ sebagai tanda suskesnya kejadian, dan $\mathrm{y}=0$ sebagai tanda tidak sesuainya kejadian. Langkah selanjutnya yaitu uji Marginal Effect, uji Goodness Of Fit Test dan uji Correctly Classified dan dilanjutkan dalam pengujian Hipotesis menggunakan aplikasi olah data Stata 14. Regresi model probit dalam penelitian ini bisa ditulis seperti berikut ini:

$$
P_{i}=\beta_{0}+\beta_{1} E M+\beta_{2} G H+\beta_{3} P D+e_{i}
$$

Keterangan :

$P_{i}:$ Probabilitas/ Peluang

$\beta_{0}:$ Konstanta

$\beta_{1}$ : Koefisien Parameter dari EM (Electronic Money)

$\beta_{2}$ : Koefisien Parameter dari GY (Gaya Hidup)

$\beta_{3}$ : Koefisien Parameter dari PD (Pengendalian Diri)

$e_{i}:$ Error

\subsection{Hasil penelitian}

Regresi probit digunakan untuk menggambarkan hubungan antar variabel dependen dan variabel independen. Model ini menjamin bahwa nilai probabilitasnya bersifat biner atau tidak linier. Berikut ialah hasil dari pengolahan data Regresi Probit yang disajikan dalam Tabel 1.1

Tabel 1.1 Hasil Regresi Probit

\begin{tabular}{lr}
\hline \multicolumn{2}{c}{ Hasil Olah Data } \\
\hline Konstanta & $-0,6939323$ \\
\hline Coef. $e$-money & $-0,3391048$ \\
\hline Coef. gaya hidup & $-0,3552996$ \\
\hline Coef. pengendalian diri & 0,6568846 \\
\hline Pseudo R2 & 0,2577 \\
\hline
\end{tabular}

Sumber : Hasil olah data Stata 14

Berdasarkan Tabel 1.1 diperoleh adanya hasil persamaan model probit sebagai berikut :

$$
\begin{gathered}
P_{i}=-0,6939323-0,3391048 e m-0,35529966 g h+ \\
0,6568846 p d+e_{i}
\end{gathered}
$$

Berdasarkan persamaan model probit menunjukkan setiap peningkatan satu nilai pada electronic money akan menurunkan kecenderungan seseorang dalam berperilaku konsumsi islam, setiap peningkatan satu nilai pada gaya hidup akan menurunkan probabilitas seseorang dalam berperilaku konsumsi secara islami, dan setiap penurunan satu nilai pada pengendalian diri akan meningkatkan probabilitas seseorang dalam berperilaku konsumsi. Tidak hanya itu, nilai -0,6939323 mengartikan bahwasannya pola perilaku konsumsi islami mempunyai nilai ejumlah angka itu tanpa terpengaruhi oleh variabel bebas lainnya yakni electronic money, gaya hidup dan pengendalian diri. Electronic money dan gaya hidup mempunyai probabilitas negatif pada pola perilaku konsumsi islam yang berarti bahwasannya semakin banyak penggunaan electronic money dan gaya hidup maka probabilitas berperilaku konsumsi konsumsi secara islam semakin rendah. Pengendalian diri memiliki probabilitas positif yang mempunyai arti semakin tinggi pengendalian diri maka probabilitas berperilaku konsumsi secara islam juga akan semakin tinggi.

Berdasarkan tabel 1.1 diketahui nilai Pseudo R2 sejumlah 0,2577 yang mengungkapkan bahwasannya model ini hanya mampu memberikan penjelasan sejumlah $25,77 \%$ pola perilaku konsumsi islam Tetapi karena hasil olah data pada regresi probit ini masih dalam bentuk index akhirnya belum dapat dipakai untuk bahan yang bisa memberikan penafsiran terkait pengaruh variabel bebas terhadap variabel terikat, perlu mencari marginal effect agar melihat dengan jelas pengaruh pengaruh itu. 
Jurnal Ilmiah Ekonomi Islam, 7(01), 2021, 213

Marginal Effect

Tabel 1.2 Hasil Marjinal efek

\begin{tabular}{lr}
\hline \multicolumn{1}{c}{ Variabel } & $\mathbf{d y} / \mathbf{d x}$ \\
\hline Coef. $e$-money & $-0,0907188$ \\
\hline Coef. gaya hidup & $-0,0950513$ \\
\hline Coef. pengendalian diri & 0,1757327 \\
\hline
\end{tabular}

Sumber: Hasil olah data Stata 14

Berdasarkan hasil dari Tabel 1.2 terlihat bahwa Marginal effect variabel e-money memiliki nilai marginal effect -9 dapat diartikan bahwa hasil yang berupa (-) lebih condong pada tidak sesuai, sehingga semakin banyak penggunaan e-money $\neg$ maka probabilitas seseorang untuk berkonsumsi islami semakin rendah yaitu 9\%. Variabel gaya hidup memiliki nilai marginal effect sebesar -9 dapat diartikan bahwa hasil yang berupa (-) lebih condong pada tidak sesuai, sehingga semakin besar gaya hidup seseorang maka probabilitas seseorang untuk berkonsumsi islami semakin rendah yaitu $9 \%$. Variabel pengendalian diri memiliki nilai marginal effect sebesar 17 dapat diartikan bahwa hasil yang berupa (+) lebih condong pada sesuai, sehingga semakin tinggi sikap pengendalian diri maka probabilitas seseorang untuk berkonsumsi islami semakin tinggi yaitu $17 \%$.

\section{Goodness Of Fit}

Pengujian Goodness of Fit Hosmer-Lemeshow digunakan untuk menentukan apakah model yang dibentuk sudah tepat atau tidak. Dikatakan tepat apabila tidak ada perbedaan signifikan antara model dan hasil observasinya. Berikut hasil perhitungan uji goodness of fit:

Tabel 1.3 Hasil Goodness of Fit Hosmer-Lemeshow

\begin{tabular}{lc}
\hline & Hasil Olah Data \\
\hline Prob Chi2 & 0,8580 \\
\hline
\end{tabular}

Sumber: Hasil olah data Stata 14

Berdasarkan tabel 1.3 memperilihatkan bahwa nilai Prob Chi2 yakni 0,8580 lebih besar dari 0,05. Maka H0 diterima dan H1 ditolak yang berarti bahwasannya model ini dapat dikatakan sesuai.

\section{Correctly Classified}

Pada aktivitas uji ini memiliki prinsip yang sama dengan uji goodness of fit sebagai bentuk perwakilan pengganti R2, dengan melakukan pengamatan melalui specitivity \& sensitivity. Berikut hasil dari correctly classified:
Tabel 1.4 Hasil Sensitivity and Specitivity

\begin{tabular}{ll}
\hline Hasil Olah Data \\
\hline Sensitivity & $45,24 \%$ \\
\hline Specitivity & $90,74 \%$ \\
\hline Correctly Classified & $78 \%$ \\
\hline
\end{tabular}

Sumber: Hasil olah data Stata 14

Berdasarkan uji ketepatan klasifikasi diperoleh hasil pada tabel 1.4 yaitu model probit yang digunakan memiliki ketepatan klasifikasi sebesar 78\%. Sehingga model dapat dikatakan sesuai atau baik karena lebih tinggi dari batas $50 \%$. Nilai sensitivity sejumlah 45,24\% memperlihatkan mengenai ketepatan model dalam melihat kejadian sukses. Sedangkan nilai specitivity memperlihatkan ketepatan model dalam melihat kejadian gagal sebesar $90,74 \%$.

\subsection{Pembahasan}

Pengaruh Variabel Electronic Money Terhadap Variabel Pola Perilaku Konsumsi Islam Generasi Y dan Z di Kota Surabaya

Berdasarkan hasil perhitungan marginal effect, variabel electronic money memiliki nilai sebesar $-9 \%$ yang menunjukan bahwa semakin tinggi electronic money maka probabilitas berperilaku konsumsi secara islami semakin rendah, sehingga dapat dinyatakan bahwa hipotesis dalam penelitian ini diterima. Hasil penelitian ini sejalan dengan penelitian terdahulu yang telah dilakukan oleh (Khairi \& Gunawan, 2019) memaparkan bahwa semakin tinggi penggunaan emoney maka terjadi peningkatan dalam pola perilaku konsumsi. Hal ini disebabkan seseorang akan lebih mudah mengeluarkan non-tunai dibandingkan dengan uang tunai.

Pada penelitian ini 90\% lebih responden mempercayai adanya electronic money adalah pembayaran yang mudah dan aman karena tidak perlu repot membawa uang. Responden juga merasa aman karena electronic money yang digunakan telah terdaftar dan memperoleh izin dari Bank Indonesia. Probabilitas pola perilaku konsumsi islam pada penelitian ini lebih rendah jika penggunaan electronic money semakin tinggi dikarenakan para generasi $\mathrm{Y}$ dan $\mathrm{Z}$ selalu melibatkan instrumen pembayaran electronic money pada setiap transaksi yang dilakukan di pusat perbelanjaan hingga mikro usaha kecil. Sebagian besar generasi $\mathrm{Y}$ dan $\mathrm{Z}$ dalam penelitian ini tidak menggunakan electronic money sebagai instrumen pembayaran dalam berzakat, infaq dan shadaqah. 
Pengaruh Variabel Gaya Hidup Terhadap Variabel Pola Perilaku Konsumsi Islam Generasi Y dan $Z$ di Kota Surabaya

Berdasarkan hasil marginal effect, variabel gaya hidup memiliki nilai sebesar $-9 \%$, gaya hidup memiliki probabilitas yang rendah dalam pola perilaku konsumsi islam. Sehingga semakin tinggi gaya hidup maka probabilitas berperilaku konsumsi secara islami cenderung rendah. Sehingga dapat dinyatakan bahwa hipotesis dalam penelitian ini diterima. Berdasarkan penelitian dilapangan $84 \%$ generasi $\mathrm{Y}$ dan $\mathrm{Z}$ mengakui bahwa dengan adanya gaya hidup baru yaitu electronic money atau gaya hidup Cashless society cenderung membuat mereka lebih koncumtif hal ini juga dikarenakan karena para generasi $\mathrm{Y}$ dan $\mathrm{Z}$ melakukan aktivitas bepergian ke pusat pembelanjaan ataupun coffe shop untuk mengisi waktu senggang mereka dan mereka juga menyukai sesuatu yang baru dan dianggap kekinian sesuai dengan gaya hidup yang terus berkembang.

Penelitian ini selaras dengan hasil penelitian yang dibuat oleh (Hasibuan, 2019) memaparkan bahwasannya masyarakat yang memiliki lingkungan dengan perilaku konsumtif dan gaya hidup yang tinggi mampu mendorong individu atau pun kelompok masyarakat melakukan hal yang serupa sesuai dengan lingkungannya.

\section{Pengaruh Variabel Pengendalian Diri Terhadap Pola Perilaku Konsumsi Islam Generasi Y dan Z di Surabaya}

Hasil uji marginal effect memperlihatkan bahwa variabel pengendakian diri berpengaruh positif terhadap pola perilaku konsumsi islam, sehingga bisa dinyatakan bahwasannya hipotesis dalam penelitian ini ditolak. Hal tersebut disebabkan para generasi $\mathrm{Y}$ dan $\mathrm{Z}$ di kota Surabaya selalu mengevaluasi gaya hidup terbaru dengan mengukur dampak yang terjadi, apakah dampak yang terjadi akan lebih baik atau lebih buruk. Dalam hal pengendalian diri para generasi Y dan $\mathrm{Z}$ melakukan penghematan ketika terlanjur membeli barang diluar perencanaan keuangan yang telah dibuat. Hasil penelitian ini tidak selaras dengan penelitian terdahulu yang telah dijalankan oleh Okky (2016) yang menyebutkan bahwasannya mahasiswa yang mempunyai pengendalian diri yang rendah akan memiliki perilaku konsumtif yang disebabkan oleh mudah terpengaruh dengan hal hal yang mendorong untuk konsumtif.

Sebanyak 89,33\% para generasi Y dan Z tidak terlalu tergiur dengan discount atau cashback pada barang yang tidak sedang dibutuhkan, para generasi $Y$ dan $\mathrm{Z}$ menahan untuk tidak membeli meski terkadang mereka sangatlah tertarik. Hal ini sesuai dengan penelitian yang dilakukan oleh (Ferinaldy et al., 2019) memaparkan bahwa semakin baik pengendalian diri yang dilakukan maka semakun baik perilaku konsumsi yang dapat dirasakan manfaatnya. Pengendalian diri yang bersifat positif menerangkan bahwa generasi $\mathrm{Y}$ dan $\mathrm{Z}$ pengguna elektronik mempunyai pengetahuan, kemampuan dan sumber yang baik dan mampu menjadikan pemakai e-money bijak dalam penggunaan instrumen pembayaran nontunai tersebut.

Generasi Y dan $\mathrm{Z}$ sebaiknya dalam mengendalikan diri agar tidak terjerat dalam konsumsi yang impulsif mengutamakan aspek pemantauan yang dapat memantau perilakunya diri sendiri agar sesuai dengan standard yang ada, aspek regulasi diri agar terhindar dari hal- hal yang dapat merugikan dirinya sendiri, dan para generasi $\mathrm{Y}$ dan $\mathrm{Z}$ harus mempunyai standar yang jelas agar dapat ditentukan besarnya anggaran yang digunakan dengan menyisihkan anggaran yang lain untuk tabungan ataupun berjagajaga.

\section{KESIMPULAN}

Penelitian ini bermaksud untuk mengetahui pengaruh electronic money, gaya hidup dan pengendalian diri terhadap pola perilaku konsum islam dengan menggunakan sampel sebanyak 150 generasi Y dan Z di Kota Surabaya. Pengolahan data yang dijalankan pada penelitian ini yaitu menggunakan aplikasi SPSS untuk uji validitas dan reabilitas serta menggunakan aplikasi Stata 14 untuk mengetahui hasil regresi probit, marginal effect, goodness of fit, dan corectly classified. Kesimpulan pada penelitian ini adalah, variable electronic money menunjukkan bahwa semakin tinggi nilai penggunaan electronic money maka probabilitas pola perilaku konsumsi secara islami semakin rendah. Sedangkan untuk variabel gaya hidup menunjukkan bahwa semakin tinggi gaya hidup maka probabilitas pola perilaku konsumsi secara islami semakin rendah, dan untuk variabel pengendalian diri menunjukkan bahwa semakin rendah nilai pengendalian diri maka probabilitas pola perilaku konsumsi secara islami semakin tinggi. 


\section{REFERENSI}

Amir, A. (2016). Pola dan Perilaku Konsumsi Masyarakat Muslim di Provinsi Jambi (Telaah Berdasarkan Tingkat Pendapatan dan Keimanan). Jurnal Perspektif Pembiayaan Dan Pembangunan Daerah, 4(2), 73-88.

Aziz, A. (2013). Etika Bisnis Perspektif Islam Implementasi Etika Islami untuk Dunia Usaha. ALfabeta.

Bank Indonesia (2020). Jumlah Uang Elektronik Beredar. https://www.bi.go.id/id/statistik/sistempembayaran/uang-elektronik/Contents/Jumlah Uang Elektronik.aspx

Bank Indonesia (2020). Uang Elektronik. Bank Indonesia. https://www.bi.go.id/id/edukasiperlindungan-konsumen/edukasi/produk-danjasa-sp/uang-elektronik/Pages/default.aspx

Choiriyah, S. (2019). Pengaruh Gaya Hidup dan Kelompok Acuan Terhadap Perilaku Konsumen Perspektif Islam. IAIN Metro Repository.

Delin, T. N. (2018). E-Money, menuju EraCashless Society. HIMA Ekonomi Pembangunan FEB UNAIR. http://himaep.feb.unair.ac.id/thinkingout-cloud/120-e-money-menuju-era-cashlesssociety.html

DeLisi, M., \& Berg, M. T. (2006). Exploring theoretical linkages between self-control theory and criminal justice system processing. Journal of Criminal Justice, 34(2), 153-163. https://doi.org/10.1016/j.jcrimjus.2006.01.005

Dikria, O., \& W., S. U. M. (2016). Pengaruh Literasi Keuangan Dan Pengendalian Diri Terhadap Perilaku Konsumtif Mahasiswa Jurusan Ekonomi Pembangunan Fakultas Ekonomi Universitas Negeri Malang. Jurusan Ekonomi Pembangunan Fakultas Ekonomi Universitas Negeri Malang, 9(434), 1-32.

Ferinaldy, F., Muslikh, M., \& Huda, N. (2019). Pengaruh Sikap, Norma Subjektif, Kendali Perilaku Dan Religiusitas Terhadap Intensi Menggunakan Uang Elektronik. Ekspansi: Jurnal Ekonomi, Keuangan, Perbankan Dan Akuntansi, 11(2), 211-222. https://doi.org/10.35313/ekspansi.v11i2.1531

Hasibuan, H. (2019). Pengaruh Pendapatan, Religiusitas Dan Gaya Hidup Terhadap Konsumsi Masyarakat Muslim Di Kecamatan Kotapinang Kabupaten Labuhanbatu Selatan.
Haws, K. L., Bearden, W. O., \& Nenkov, G. Y. (2012). Consumer spending self-control effectiveness and outcome elaboration prompts. Journal of the Academy of Marketing Science, 40(5), 695-710. https://doi.org/10.1007/s11747011-0249-2

Kemenppa, BPS. (2018). Profil Generasi Milenial Indonesia.

Khairi, M. R., \& Gunawan, E. (2019). Analisis Penggunaan Alat Pembayaran Menggunakan Kartu (APMK) dan E-Money Terhadap Konsumsi Masyarakat di Banda Aceh. Jurnal Ilmiah Mahasiswa Ekonomi Islam, 1, 19-36.

Kupperschmidt, B. R. (2000). 2000 Imp Multigenerational Employees: Strategies for Effective Management. The Health Care Manager.

Malhotra, N. K. (2009). Riset Pemasaran: Pendekatan Dan Terapan Jilid 1. PT. Index.

Mardian Suryani, S. A. (2019). Gaya Hidup Hedonisme Dalam Konsumsi Ditinjau dari Perspektif Ekonomi Islam (Studi Pada Mahasiswi Jurusan Ekonomi Islam IAIN Kota Bengkulu). Al-Intaj, 5(2), 15-16.

Pujiyono, A. (2006). Teori Konsumsi Islami. Dinamika Pembangunan, 3(2), 196-207.

Rahman, A., \& Fitrah, M. (2018). Perilaku Konsumsi Masyarakat Dalam Perspektif Islam Di Kelurahan Barombong Kota Makassar. LAA MAISYIR : Jurnal Ekonomi Islam, 5(1), 18-42. https://doi.org/10.24252/laamaisyir.v5i1a1

Ramadhani, R. H. (2019). Pengaruh Literasi Keuangan, Electronic Money, Gaya Hidup, dan Kontrol Diri Terhadap Perilaku Konsumtif Mahasiswa. Repositori Institusi USU, Univsersitas Sumatera Utara, 114.

Rif'ah, S. (2019). Fenomena Cashless Society Di Era Milenial Dalam Perseektif Islam. Al-Musthofa: Journal of Sharia Economics, 2(3), 1-9.

Shihab, Q. (n.d.). Tafsir Surat Al-A'raf Ayat 31. Retrieved March 15, 2020, from https://tafsirq.com/7-al-araf/ayat-31\#tafsirquraish-shihab

Suprapti, N. W. S. (2010). Perilaku Konsumen. Udayana University Press.

Suwarman, U. (2004). Perilaku Konsumen. Penerbit Ghalia Indonesia.

Yuliadi, I. (2001). Ekonomi Islam Sebuah Pengantar. Lembaga Pengkajian dan Pengalaman Islam. 